\begin{tabular}{c|c|c} 
ISSN 2525-4812 (versão online) & Recebido em: 31/5/2020 & Revista Terceira \\
ISSN 2238-7641 (versão impressa) & Aprovado para Sober 2020: 23/7/2020 & Margem Amazônia \\
http://www.revistaterceiramargem.com/ & Aceito para RTMA: 25/4/2021 & Pán \\
index.php/terceiramargem/index & Período de publicação: jan./jul. 2021 & (v. 7 • n. 17 • Jan./Jun. 2021) \\
\hline
\end{tabular}

Como citar o artigo:

MARRA, L. A. F.; MIYAMOTO, B. C. B.; SILVA JUNIOR, J. J. da. Acordo de Paris e a política nacional de biocombustíveis: estimação da receita gerada na agroindústria da cana com a comercialização de créditos de descarbonização. Revista Terceira Margem Amazônia, v. 7, n. 17, p. 93-109, 2021. DOI: http://dx.doi.org/10.36882/2525-4812.2021v7i17.p93-109

\title{
ACORDO DE PARIS E A POLÍTICA NACIONAL DE BIOCOMBUSTÍVEIS: ESTIMAÇÃO DA RECEITA GERADA NA AGROINDÚSTRIA DA CANA COM A COMERCIALIZAÇÃO DE CRÉDITOS DE DESCARBONIZAÇÃO
}

\author{
Layane Andréa Ferreira Marra \\ Bruno César Brito Miyamoto ${ }^{2}$ \\ Jaim José da Silva Junior ${ }^{3}$
}

\begin{abstract}
Resumo: O objetivo geral do presente trabalho é apresentar e discutir o papel dos biocombustíveis nas contribuições brasileiras ao Acordo de Paris. Para isso, o artigo irá analisar a Política Nacional de Biocombustíveis (RenovaBio), instituída pela Lei $n^{\circ}$ 13.576/2017, que busca promover a descarbonização do setor de transportes e incentivar a produção de combustíveis sustentáveis. O objetivo específico do estudo é estimar a receita que unidades produtoras (UPs) de biocombustíveis poderão obter com a comercialização de créditos de descarbonização (CBIOs). Com base em amostra composta por dados da produção de etanol de cana hidratado em 161 unidades diferentes, e apoiado na regulamentação institucionalizada pela RenovaBio, o estudo estima a quantidade de CBIOs emitidos. O valor do CBIO mimetiza aquele praticado na comercialização de toneladas de carbono equivalente (tCO2 eq.) em outros países. Os resultados indicam que, ao preço de US\$ 25/tCO2 eq., a comercialização de CBIOs teria gerado uma receita adicional de $\mathrm{R} \$ 0,15$ por litro de etanol hidratado produzido em 2019. Além disso, foi possível constatar que a escala de produção de biocombustível exerce grande influência sobre o nível de créditos de descarbonização obtido pelas usinas.
\end{abstract}

Palavras-chave: mudanças climáticas, RenovaBio, tonelada de carbono equivalente, créditos de descarbonização.

\footnotetext{
Cientista política, doutora em Planejamento Urbano e Regional, professora da Universidade Federal de Rondônia (Unir), Porto Velho, R. E-mail: layaneandrea@hotmail.com

(D) http://orcid.org/0000-0002-5159-3825

2 Sociólogo, Especialização em Sociologia e Ensino de Sociologia, professor da Secretaria de Estado de Educação de Rondônia (Seduc), Porto Velho, RO. E-mail: miyamototup@gmail.com

(iD https://orcid.org/0000-0002-8977-3581

3 Sociólogo, Especialização em Sociologia e Ensino de Sociologia, professor da Secretaria de Estado de Educação de Rondônia (Seduc), Porto Velho, RO. E-mail: jaim@unb.br.

(iD https://orcid.org/0000-0003-0201-3537
} 


\title{
PARIS AGREEMENT AND THE NATIONAL BIOFUELS POLICY: ANALYSIS OF THE REVENUE GENERATED FROM THE COMMERCIALIZATION OF DECARBONIZATION CREDITS
}

\begin{abstract}
The general objective of this paper is to discuss the role of biofuels in Brazilian contributions to the Paris Agreement. To this end, it is presented the main instruments of the RenovaBio - Law No. 13,576 / 2017, which seeks to promote the decarbonisation of the transport sector and encourage the production of sustainable fuels. The specific objective of the study is to estimate the revenue that units producing biofuels can obtain from the commercialization of decarbonization credits (CBIOs), in three different carbon price scenarios. The production units of the sample were grouped in clusters according to the proximity observed for four variables: total cane area, quantity of cane processed, quantity of ethanol produced and quantity of CBIOs generated. Clustering, carried out with the K-means algorithm, makes it possible to analyze in aggregate plants with similar characteristics of ethanol production and energyenvironmental efficiency. The results indicate that in the optimistic scenario, with a price of US \$ 25 per ton of carbon equivalent, the plants will receive $\mathrm{R} \$ 0.15$ per liter of hydrated ethanol.
\end{abstract}

Keywords: climate change, RenovaBio, ton of carbon equivalent, decarbonization credits.

\section{Introdução}

Há registro de mudanças climáticas causadas por dinâmicas naturais que perduraram bilhões de anos. As mudanças desse tipo, como, por exemplo, os períodos glaciais, foram determinantes para a evolução do planeta Terra (DA COSTA SILVA; DE PAULA, 2009; LEITE, 2015; MOLION, 2008). Por outro lado, nos últimos 2 séculos, o crescimento acelerado das emissões de gases de efeito estufa (GEE) por atividades antrópicas tem provocado mudanças climáticas de forma desequilibrada, com impactos negativos sobre o planeta e a sociedade (ONU, 2015). Diante dos resultados indesejados, países e organizações multilaterais se empenharam, ao longo das últimas décadas, para elaborar um entendimento comum da questão climática. Em decorrência dessas ações, pode-se afirmar que a implementação de acordos internacionais para redução das emissões antrópicas de GEE tornou-se um dos principais instrumentos utilizados para impedir o aquecimento global e as mudanças climáticas (BRASIL, 2016b; RAMSTEIN et al., 2019).

A principal organização global voltada à tomada de decisões para intervenções coordenadas sobre as mudanças climáticas é a Convenção-Quadro das Nações Unidas sobre Mudanças Climáticas (UNFCCC), instituída durante a Cúpula da Terra (ECO-92) em 1992, no Rio de Janeiro. Seu principal objetivo é estabilizar a concentração de GEE no nível que impeça a interferência humana incerta no sistema climático, dentro de um prazo que permita a adaptação dos ecossistemas e o desenvolvimento sustentável, sem ameaçar a produção de alimentos (ONU, 2015; VITAL, 2018).

Desde a sua origem, o UNFCCC conta com a participação de quase todos os países do mundo, que se reúnem anualmente nas Conferências das Partes (COPs) para tomar decisões coletivas e consensuais sobre a governança global das mudanças climáticas. As ações propostas pelo UNFCCC, estabelecidas nas diversas COPs, são apoiadas em pesquisas científicas e estudos avaliados no âmbito do Painel Intergovernamental sobre Mudanças Climáticas (IPCC). Segundo o IPCC, é "extremamente provável” que a alta concentração de GEE seja a causa dominante do aquecimento global observado desde meados do século XX, e a continuidade dessas emissões 
nos patamares atuais levará a mais aquecimento e alterações nos componentes do sistema climático, aumentando a probabilidade de impactos severos e irreversíveis para pessoas e ecossistemas (IPCC, 2019; ONU, 2015).

Firmado no ano de 2015, durante a $21^{\mathrm{a}}$ Conferência das Partes (COP21) da UNFCCC, o Acordo de Paris é o acordo climático global vigente, que coordena a atuação dos países signatários. Com o Acordo de Paris, governos nacionais se comprometeram a lançar medidas e ações para manter o aumento da temperatura mundial abaixo de $2{ }^{\circ} \mathrm{C}$ em relação aos níveis pré-industriais e a empregar esforços para limitar o aumento da temperatura a $1,5^{\circ} \mathrm{C}$, quando comparada ao mesmo momento da história. Aos signatários coube desenvolver planos nacionais de redução das emissões de GEE, que passarão a vigorar em 2020, materializados no documento oficial denominado "Contribuições Pretendidas e Nacionalmente Determinadas" (Intended Nationally Determined Contribution - iNDC, (RAHTMANN et al., 2017; REI et al., 2017).

O governo brasileiro apresentou sua iNDC à UNFCCC em 27 de setembro de 2015, reconhecendo a necessidade da implementação de medidas para mitigar as emissões de GEE e evitar o aquecimento global. Em setembro de 2016, a Contribuição Nacionalmente Determinada (NDC) do Brasil deixou de ser "pretendida", e suas metas de mitigação se tornaram obrigações a serem cumpridas. A NDC brasileira prevê o fortalecimento de ecossistemas e sistemas produtivos, bem como a provisão de serviços ambientais como parte dos esforços nacionais para reduzir as emissões de GEE (BRASIL, 2016a; MARCOVITH et al., 2019).

O objetivo geral do presente trabalho é apresentar e discutir o papel dos biocombustíveis na NDC brasileira. Para isso, o artigo irá analisar a Política Nacional de Biocombustíveis (RenovaBio), instituída pela Lei $n^{\circ} 13.576 / 2017$, que busca promover a descarbonização do setor de transportes e incentivar a produção de combustíveis sustentáveis no País ((BRASIL, 2017a; PEREIRA et al., 2018). O objetivo específico é estimar a receita que unidades produtoras de biocombustíveis poderão obter com a comercialização de créditos de descarbonização (CBIOs), levando em consideração três diferentes cenários do preço de comercialização da tonelada de carbono equivalente (BRASIL, 2017b; MATSUURA et al., 2018).

As usinas da amostra foram agrupadas em clusters de acordo com a proximidade observada para quatro variáveis: área total de cana-de-açúcar, quantidade de cana-de-açúcar processada, quantidade de etanol produzida e quantidade gerada de CBIOs. A clusterização, feita com o algoritmo $K$-means, torna possível analisar de forma agregada usinas com características semelhantes na produção de etanol e na eficiência energético-ambiental, sendo a variável quantidade gerada de CBIOs uma proxy da eficiência energético-ambiental das usinas. A quantidade de CBIOs será utilizada para avaliar a receita obtida pelas usinas, dados os preços de comercialização da tonelada de carbono equivalente nas simulações. Os dados das usinas empregados na avaliação empírica foram disponibilizados em consultas públicas por empresas certificadoras da produção de biocombustíveis. Já os preços da tonelada de carbono equivalente empregados no estudo assemelham-se aos praticados em mercados de carbono da China, Argentina e União Europeia.

Em busca dos objetivos propostos, o artigo está dividido em cinco partes. Após a introdução, o item 2 traça uma linha do tempo dos encontros e acordos climáticos globais que culminaram na celebração do Acordo de Paris. O item 3 analisa o papel dos biocombustíveis na NDC 
brasileira e apresenta as principais metas e instrumentos propostos pela RenovaBio. O item 4 divulga os materiais e métodos empregados na clusterização e na avaliação da receita obtida com a comercialização de CBIOs. O item 5 apresenta e discute os resultados do estudo. A conclusão resgata as principais contribuições da pesquisa no âmbito dos esforços brasileiros de descarbonização no setor de combustíveis e aponta para possíveis desdobramentos na forma de estudos futuros.

\section{Histórico de acordos climáticos globais}

As ações para conter as mudanças climáticas são marcadas por inúmeros esforços diplomáticos, que em um primeiro momento tiveram como objetivo principal a preservação do meio ambiente. A Conferência das Nações Unidas sobre o Meio Ambiente, realizada em 1972 na Suécia, resultou na Declaração de Estocolmo e na criação do Programa das Nações Unidas para o Meio Ambiente. Com a anuência de representantes de 113 países, que firmaram compromissos pela preservação do meio ambiente, a declaração estipulou 26 princípios e 109 recomendações de ação.

Em 1979, ocorreu a Primeira Conferência Mundial do Clima, estabelecida pela Organização Meteorológica Mundial (OMM), da qual participaram cientistas e especialistas de 53 países e 24 organizações internacionais. A conferência teve como foco pesquisas ligadas aos fenômenos climáticos e possíveis impactos de mudanças climáticas sobre a agricultura, os recursos hídricos, a economia, dentre outros.

Ao longo dos anos, o acúmulo de conhecimento relacionado à questão climática resultou na criação, pela ONU, em 1988, do Painel Intergovernamental sobre Mudanças Climáticas (IPCC). O IPCC é uma organização que busca avaliar e certificar pesquisas científicas sobre mudanças climáticas. No mesmo ano foi aprovada, em Assembleia Geral da ONU, a criação do Comitê Intergovernamental de Negociações (CIN), responsável pela elaboração de uma Convenção das Nações Unidas sobre as Mudanças Climáticas.

Em 1990, mais de uma década após a primeira conferência mundial, foi realizada a Segunda Conferência Mundial do Clima com intuito de avaliar e atualizar as decisões tomadas em 1979. O conjunto de evidências científicas acumuladas no período entre as conferências fortaleceu a percepção do processo de aquecimento global e incentivou a formulação de medidas e ações que visavam ao retardamento desse fenômeno, assim como seus impactos negativos sobre a sociedade, a economia e o meio ambiente.

Na ECO 92 foram estipuladas as medidas necessárias para a criação de um tratado climático internacional que estabelecesse entre seus signatários um entendimento comum sobre a questão climática global. Nesse contexto foi criada a Convenção-Quadro das Nações Unidas sobre Mudanças do Clima (UNFCCC), que originalmente contou com a participação de 172 países. A ratificação do UNFCCC em 1994 passou a ter 196 países-membros e definiu o papel das nações no controle do aquecimento global e estipulou a realização das COPs.

A primeira conferência das partes, em Berlim (COP1/1995), resultou na criação do Mandato de Berlim, que reforçou o papel dos países desenvolvidos na reversão das mudanças climáticas. 
Além disso, na COP1, foi estipulado o prazo de 2 anos para a negociação de um acordo que definisse metas de redução de emissões de gases de efeito estufa. Vale ressaltar que as metas estabelecidas na COP1 buscavam mais do que a estabilização dos GEE, visavam à redução absoluta das emissões nos países desenvolvidos.

Como resultado dos compromissos firmados na COP1, estabeleceu-se o Protocolo de Quioto na COP3, em 1997. Com o Protocolo de Quioto, 37 países desenvolvidos reconheceram que são os principais causadores da poluição atmosférica registrada nos 150 anos anteriores e, por isso, devem empreender os maiores esforços para conter o aquecimento global. O Protocolo de Quioto estipulou os primeiros mecanismos e objetivos específicos para redução das emissões globais de GEE, como, por exemplo, o Mecanismo de Desenvolvimento Limpo (MDL) e o Comércio de Emissões de GEE.

Em 2002, na COP8, em Nova Délhi (Índia), foi redigido o documento RIO+10, que abordou, no âmbito das mudanças climáticas, temas como energias renováveis, biodiversidade, desertificação, entre outros. Concomitantemente à COP8, a Segunda Cúpula Mundial sobre o Desenvolvimento Sustentável resultou na Declaração de Joanesburgo, que atualizou as resoluções climáticas anteriores e incluiu de forma definitiva o aquecimento global no paradigma do desenvolvimento sustentável.

Em 2005 passou a vigorar o Protocolo de Quioto, ratificado por 192 países. No mesmo ano teve início o período para os países atingirem suas metas de redução de emissões. Em 2008 foi aceita a flexibilização do Protocolo de Quioto, tornando o cumprimento das metas de descarbonização politicamente sustentáveis pelas nações participantes e permitindo o comércio de emissões de créditos de carbono entre países desenvolvidos e os em desenvolvimento. Mesmo com a flexibilização, o Protocolo de Quioto não obteve os resultados esperados.

Em 2009, a Declaração de Copenhague estipulou metas climáticas alternativas àquelas vigentes no Protocolo de Quioto. Além disso, não buscou envolver de forma voluntária todos os países nas metas de redução. Mesmo com a flexibilização das metas, a Declaração de Copenhague não obteve consenso das partes no UNFCCC e, por esse motivo, não foi posta em assinatura. Em 2010, a Declaração de Cancún, assinada por 195 países, detalhou e expandiu os objetivos e medidas estipulados em Copenhague, passando a ser adotada formalmente pela UNFCCC.

No ano de 2015, o Acordo de Paris foi assinado, como sucessor do Protocolo de Quioto, tendo como grande mudança a adoção de metas voluntárias e o incentivo à redução de emissões de GEE em todas as nações. A Figura 1 apresenta de forma esquemática a linha do tempo que abrange os acordos e reuniões multilaterais relacionados à questão das mudanças climáticas.

Para alcançar os objetivos elencados no Acordo de Paris, os governos nacionais elaboraram suas Contribuições Pretendidas e Nacionalmente Determinadas (Intended Nationally Determined Contribution - iNDC). O intended do nome explica-se pelo fato de o documento ser uma intenção de mudanças ainda não oficial, de caráter voluntário. Uma vez ratificada pela UNFCCC e pelos governantes, a iNDC passa a ser denominada exclusivamente de NDC. Um compromisso firmado, de fato, pelos países e obrigatório a partir de 2020 (IPCC, 2019). 
Figura 1. Linha do tempo de encontros e acordos climáticos.

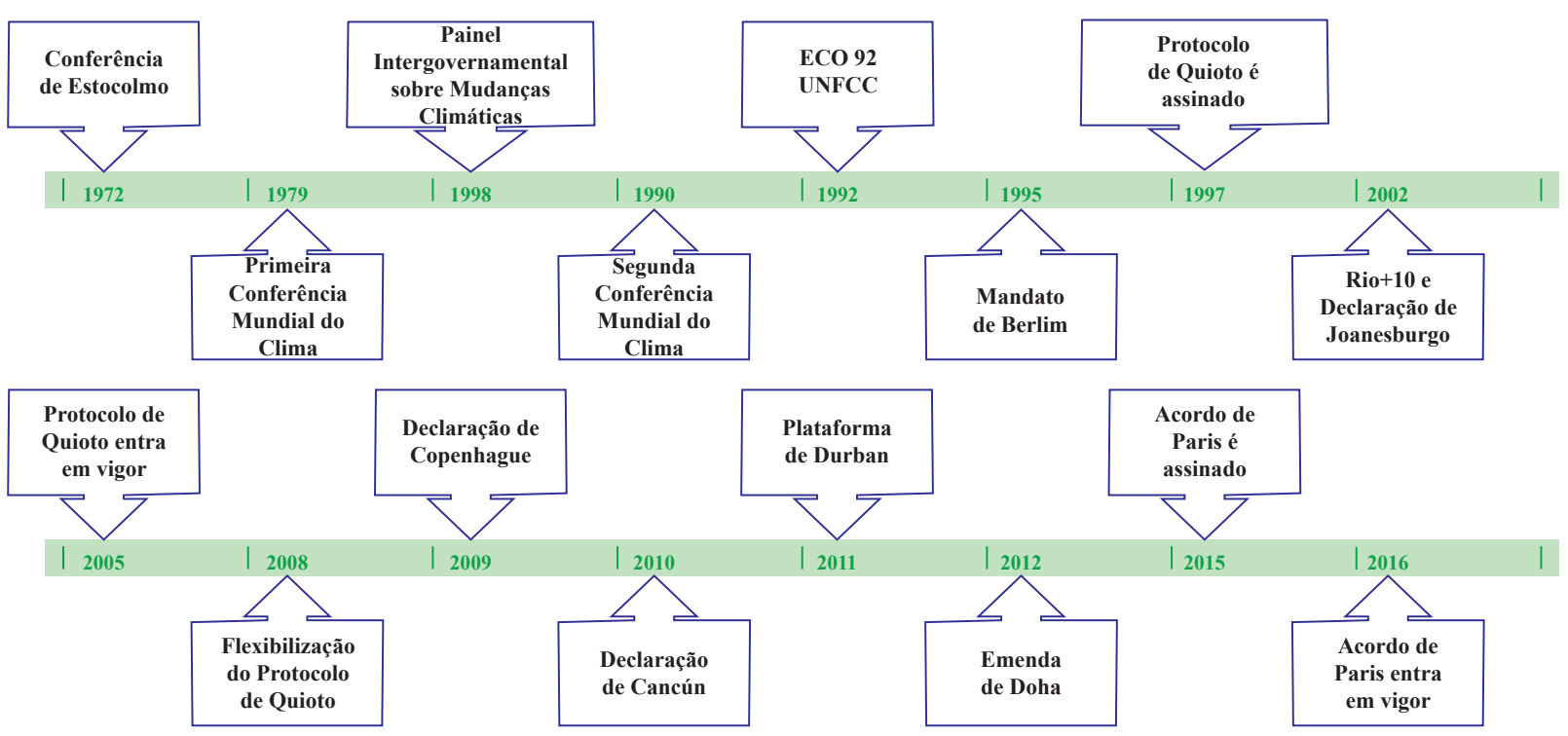

Fontes: IPCC (2019); dados da pesquisa (2020).

O NDC é um documento que reflete as ambições de cada país para a redução de emissões dos gases de efeito estufa, fomentando ao mesmo tempo o desenvolvimento sustentável, seguindo o que cada governo considera viável a partir do cenário social e econômico local para alcance de uma mitigação geral das emissões globais. O NDC assume metas quantificáveis de emissões e parâmetros que permitam comparar as diferentes contribuições, além de informar que tipo de apoio o país precisará ou fornecerá para alcançar seus objetivos (BRASIL, 2016a; IPCC, 2019).

A decisão 1/COP-20 estipula que as comunicações das NDCs podem incluir, conforme o caso, informações quantificáveis sobre o ponto de referência (incluindo, se necessário, um ano de referência), períodos de implementação, escopo e abrangência, premissas e abordagens metodológicas, entre outros aspectos, sendo que os países devem também inserir no documento considerações sobre as ambições e o equilíbrio da NDC à luz das circunstâncias nacionais. A soma das NDCs de todos os países signatários do Acordo de Paris é fundamental para determinar se o mundo está caminhando na direção de uma economia de baixo carbono, capaz de mitigar as alterações climáticas.

\section{Contribuição Nacionalmente Determinada (NDC) brasileira e a indústria de biocombustíveis}

\section{Elaboração e estrutura da NDC brasileira}

O governo brasileiro apresentou sua iNDC à UNFCCC em 27 de setembro de 2015, reconhecendo a necessidade da implementação de políticas públicas para adaptação às mudanças climáticas, à preservação de ecossistemas, bem como garantia e manutenção da provisão de serviços ambientais. As políticas e os instrumentos para implementação da iNDC brasileira foram baseados, sobretudo, em seis normativos (e seus derivados) principais (BRASIL, 2016a; RATHMANN et al., 2017): 
- Política Nacional sobre Mudança do Clima (Lei n 12.187, de 29 de dezembro de 2009).

- Código Florestal (Lei n ${ }^{\circ}$ 12.651, de 25 de maio de 2012).

- Sistema Nacional de Unidades de Conservação (Lei nº 9.985, de 18 de julho de 2000).

- Política Nacional de Resíduos Sólidos (Lei nº 12.305, de 2 de agosto de 2010).

- Plano Setorial de Mitigação e de Adaptação às Mudanças Climáticas para a Consolidação de uma Economia de Baixa Emissão de Carbono na Agricultura.

- Plano Setorial de Mitigação e de Adaptação às Mudanças Climáticas para a Consolidação de uma Economia de Baixa Emissão de Carbono (Plano ABC) (Decreto n ${ }^{\circ} 7.390$, de 9 de dezembro de 2010).

Na iNDC o País assumiu compromissos para reduzir as emissões de GEE em 37\% até 2025, com uma contribuição indicativa subsequente de redução de $43 \%$ até 2030 em relação aos níveis de emissões estimados para 2005, tendo como referência as emissões reportadas na Segunda Comunicação Nacional do Brasil à UNFCCC. Para isso, a iNDC brasileira estipula metas de mitigação em diversos setores da economia até o ano de 2030, com destaque para os seguintes tópicos (BRASIL, 2016a):

1) No setor de biocombustíveis:

- Aumentar a participação da biomassa na matriz energética brasileira para aproximadamente $18 \%$, por meio da expansão do consumo de biocombustíveis, a oferta de etanol e biodiesel.

2) No setor de energia:

- Alcançar a participação de $45 \%$ de energias renováveis na composição da matriz energética em 2030.

- Expandir o uso doméstico de fontes renováveis de energia, além da hidroelétrica, para ao menos $23 \%$, inclusive pelo aumento da participação de eólica, biomassa e solar.

- Aumentar em ao menos 10\% a eficiência no setor elétrico.

3) No setor florestal e de mudança do uso da terra:

- Fortalecer o cumprimento do Código Florestal, em âmbito federal, estadual e municipal.

- Fortalecer políticas e medidas com vistas a alcançar, na Amazônia Brasileira, o desmatamento ilegal zero em 2030 e a compensação das emissões de gases de efeito estufa provenientes da supressão legal da vegetação.

- Restaurar e reflorestar 12 milhões de hectares de floresta, para múltiplos usos. 
- Ampliar a escala de sistemas de manejo sustentável de florestas nativas, por meio de sistemas de georreferenciamento e rastreabilidade aplicáveis ao manejo de florestas nativas, com vistas a desestimular práticas ilegais e insustentáveis.

4) No setor agrícola:

- Fortalecer o Plano ABC como a principal estratégia para o desenvolvimento sustentável na agricultura, inclusive por meio da restauração adicional de 15 milhões de hectares de pastagens degradadas e o incremento de 5 milhões de hectares de sistemas de integração lavoura-pecuária-florestas (ILPF).

5) No setor industrial:

- Promover novos padrões de tecnologias limpas e ampliar medidas de eficiência energética e de infraestrutura de baixo carbono.

Em setembro de 2016, a NDC do Brasil deixou de ser "pretendida", e as metas de mitigação estipuladas se tornaram obrigações a serem cumpridas. De acordo com o objetivo deste trabalho, será analisada, a seguir, a RenovaBio, implantada pelo governo federal, diante do compromisso assumido no Acordo de Paris, tendo como objetivo a busca de respostas às mudanças climáticas e a descarbonização do setor nacional de combustíveis, especialmente na etapa da distribuição (FARINA et al., 2019; JARDIM, 2018).

\section{RenovaBio: Créditos de Carbono, RenovaCalc e Certificação}

Com vistas à sustentabilidade do mercado brasileiro de combustíveis, e tendo como principal medida a substituição de combustíveis fósseis, o Ministério de Minas e Energia (MME) instituiu, pela Lei n ${ }^{\circ} 13.576$ de 2017, a RenovaBio, política que busca expandir a produção de biocombustíveis com base na sustentabilidade ambiental, econômica e social, incentivar investimentos em novas tecnologias sustentáveis para que o setor ganhe eficiência e competitividade (BRASIL, 2017a, 2017b). Essa política nacional foi elaborada em conjunto por representantes do setor sucroenergético, de distribuidores de combustíveis e do setor público, lideranças do agronegócio e diversos segmentos que integram o abastecimento nacional de combustíveis.

Afirma-se que a RenovaBio transforma a expansão da indústria brasileira de biocombustíveis em um instrumento para se alcançar as metas de descarbonização estipuladas no NDC. Um dos argumentos-chave para a formulação da RenovaBio parte do pressuposto de que há uma estagnação na indústria brasileira de refino de petróleo, incapaz de suprir a expansão projetada para a demanda nacional de combustíveis. A execução do programa está apoiada em três instrumentos (BRASIL, 2017b; NASTARI, 2019):

1) Metas anuais de redução da intensidade de carbono por unidade de energia (gCO2/MJ), estipuladas por períodos de 10 anos ao setor de distribuição de combustíveis.

2) A certificação da produção de biocombustíveis, usada para avaliar a intensidade de carbono e atribuir a nota de eficiência energético-ambiental (EEE) de cada unidade de produção de biocombustíveis. 
3) O crédito de descarbonização (CBIO), emitido para a unidade de produção certificada e baseado em sua nota de eficiência energético-ambiental.

A Política Nacional de Biocombustíveis incentiva a redução das emissões de GEE na produção de biocombustíveis ao possibilitar que usinas obtenham receitas adicionais com a comercialização dos créditos de descarbonização. A nota de eficiência e a quantidade de biocombustível produzido são as variáveis-chave no cálculo do total de CBIOs a que cada usina terá direito. Avaliada pela ferramenta RenovaCalc, que utiliza modelos de análise de ciclo de vida (ACV), a nota de eficiência energético-ambiental mensura as emissões de GEE no processo de produção dos biocombustíveis. Dessa forma, o volume de CBIOs emitido por unidade produtora está diretamente relacionado à quantidade de energia limpa produzida e irá constituir um ativo financeiro negociado no mercado de capitais, ofertado por produtores de biocombustível e demandado por empresas distribuidoras de combustíveis (MATSUURA et al., 2019; SCACHETT et al., 2018b).

Conforme estipulado na RenovaBio, as firmas distribuidoras de combustíveis terão que adquirir CBIOs no montante necessário para cumprir suas metas anuais compulsórias de descarbonização. Segundo a Resolução n ${ }^{0}$ 8, de 18 de agosto de 2020, do Conselho Nacional de Política Energética (CNPE), a meta de descarbonização da indústria de distribuição de combustíveis estipulada para o ano de 2020 é de 28,7 milhões de CBIOs, o correspondente a 28,7 mi1hões de toneladas de carbono equivalente ( $\mathrm{tCO} 2 \mathrm{eq})$. Vale destacar que três empresas - Petrobrás Distribuidora, Ipiranga e Raízen - serão responsáveis pela aquisição de 18,7 milhões de CBIOs ou $65 \%$ da demanda nacional de créditos de carbono.

Para obterem a certificação e lançarem CBIOs no mercado, as unidades produtoras de biocombustíveis deverão ser inspecionadas por empresas certificadoras credenciadas na Agência Nacional de Petróleo, Gás Natural e Biocombustíveis (ANP), que irão avaliar a eficiência energético-ambiental do processo de produção, com o uso da RenovaCalc (ASSOCIAÇÃO BRASILEIRA DAS ENTIDADES DOS MERCADOS FINANCEIRO E DE CAPITAIS, 2019; SCACHETT et al., 2018a). O resultado do processo de certificação tem a validade de 4 anos.

Com relação à oferta dos títulos de descarbonização, até o momento da redação deste artigo, consta que aproximadamente 200 unidades produtoras estão participando do processo de certificação.

\section{Materiais e Métodos}

O presente estudo utiliza informações secundárias das unidades produtoras de biocombustíveis, disponibilizadas em consultas públicas do processo de certificação da produção e emissão de CBIOs. Os dados foram coletados ao longo do ano de 2019 e início de 2020 junto às empresas certificadoras e compreendem informações pertinentes às etapas agrícola, industrial e de distribuição do sistema de produção de biocombustíveis.

A amostra utilizada no estudo é composta exclusivamente por unidades produtoras de etanol de cana-de-açúcar hidratado, embora informações sobre unidades produtoras de biodiesel de soja e etanol de milho também tenham sido disponibilizadas nas consultas públicas. Ao total, a 
amostra reuniu dados de 161 unidades produtoras, que em conjunto corresponderam a aproximadamente $60 \%$ da área cultivada com cana e $50 \%$ do total de cana processada no País em 2019.

O método de clusterização K-means, presente no pacote estatístico Factoextra da plataforma $\mathrm{R}$, foi utilizado para classificar os elementos da amostra em grupos de características semelhantes. Com isso, as usinas foram agrupadas em quatro clusters de acordo com a proximidade dos valores das variáveis observados: área total de cana, quantidade de cana processada, quantidade de etanol produzida e quantidade de CBIO gerada. A clusterização permite comparar elementos com características similares e aumentar a capacidade de análise dos resultados.

Os preços da tonelada de carbono equivalente empregados na construção dos cenários da receita tiveram como referência os preços observados em esquemas de comercialização de emissões (EST) e taxas de carbono, detalhados em Ramstein et al. (2019). Optou-se por manter os valores em moeda estrangeira nominal (dólares), por motivo da significativa oscilação da cotação da moeda brasileira (real) registrada ao longo de 2019 e 2020. A metodologia usada para calcular a quantidade de CBIOs atribuídos às unidades produtoras segue aquela apresentada em Brasil (2017b, p. 59) e pode ser descrita da seguinte forma:

Qtd. de CBIOs $=[($ Qtd. de biocombustivel produzido $*$ Fator de Conversão $) *$ Nota de Eficiência Energético-Ambiental)]

em que:

Qtd. de CBIOs = número de créditos de descarbonização obtido por usina. Cada CBIO equivale à retirada de 1 tonelada de carbono equivalente da atmosfera.

Qtd. de biocombustivel produzido = total de litros de etanol produzido por usina.

Fator de conversão = quantidade de energia contida em um litro de biocombustível. De acordo com Brasil (2017b), um litro de etanol hidratado contém 21,35 MJ.

Eficiência Energético-Ambiental = definida em função da diferença entre a intensidade de carbono da usina e a intensidade de carbono do combustível fóssil substituto por biocombustíveis com quantidade de energia semelhante. A nota de eficiência energética ambiental é auferida no processo de certificação com o uso da RenovaCalc e tem validade de 4 anos.

Com base nessa metodologia, pode-se inferir que as unidades produtoras que alcançarem as maiores notas de eficiência energético-ambiental e produzirem maiores volumes de biocombustíveis terão direito a uma maior quantidade de CBIOs.

A Resolução no 8, de 18 de agosto de 2020, do Conselho Nacional de Política Energética (CNPE) estabeleceu as metas de descarbonização das empresas de distribuição de combustíveis. As metas individuais de descarbonização são calculadas a partir da participação das empresas no mercado brasileiro de distribuição do ano anterior. Com isso, empresas com maiores fatias do mercado de distribuição de combustíveis terão que comprar maiores quantidades de CBIOs.

A revisão bibliográfica teve como base artigos e reportagens sobre o tema, disponíveis em periódicos científicos e veículos de comunicação especializados no setor de biocombustíveis. 
Vale ressaltar que poucas pesquisas adotaram a RenovaBio como objeto principal de estudos. O presente artigo visa suprir essa lacuna e contribuir para o fortalecimento do mercado de créditos de carbono no País.

\section{Resultados e Discussão}

As 161 empresas da amostra processaram o total de 398 milhões de toneladas de cana-de-açúcar e cultivaram área de 7,3 milhões de hectares em 2019. Conforme exposto na Figura 2, metade das empresas da amostra processou menos do que 2,3 milhões de toneladas de cana-de-açúcar e utilizou área inferior a 37,5 mil hectares, sendo que apenas $25 \%$ das unidades obtiveram valores de processamento superiores a 3,2 milhões de toneladas e área cultivada maior do que 56 mil hectares.

Figura 2. Estatísticas descritivas da produção de biocombustíveis.
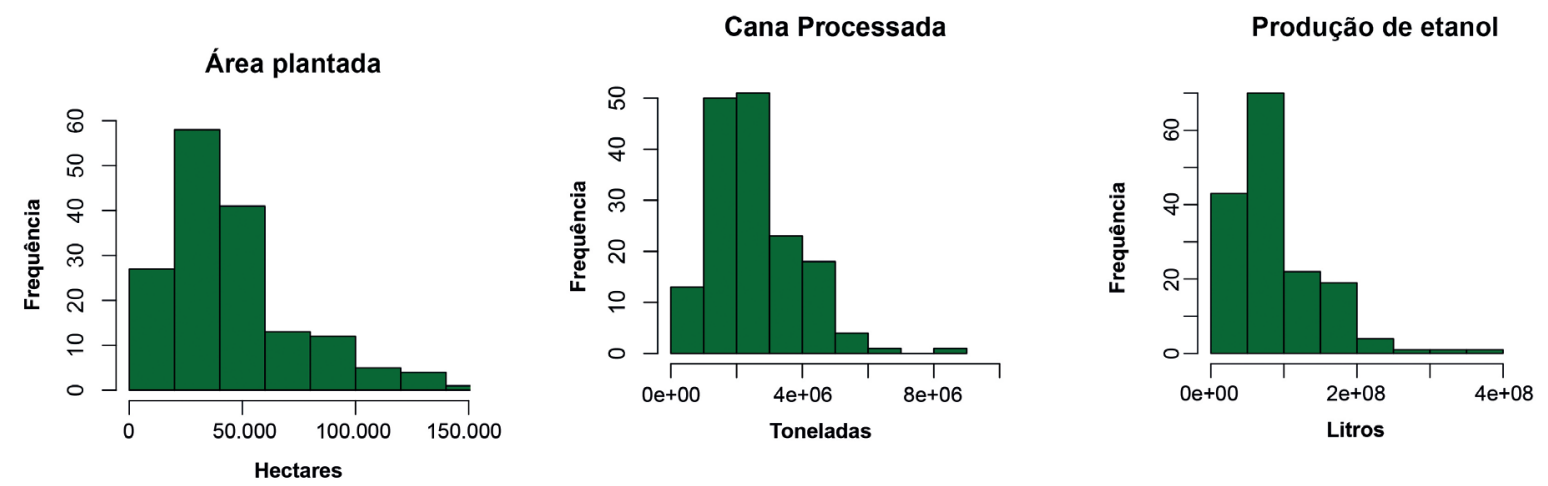

Fonte: Consulta Pública RenovaBio; dados da pesquisa $(2019 ; 2020)$.

Essa heterogeneidade também pôde ser observada na produção de etanol e na geração de créditos de descarbonização. Embora a produção média das 161 usinas tenha sido de 88,8 mi1hões de litros, metade das usinas apresentou produção inferior a 76 milhões de litros. Conforme consta na Figura 3, somente 25\% das empresas produziram quantidade de etanol superior a 110 milhões de litros. No caso dos CBIOs, as empresas geraram o total de 18,6 milhões de CBIOs, sendo que $25 \%$ das unidades geraram menos do que 58 mil CBIOs, $50 \%$ menos do que 97 mil CBIOs e 25\% mais do que 138 mil CBIOs (Figura 3).

O Anexo I apresenta a intensidade de carbono em cada etapa da produção de etanol hidratado nas 161 usinas da amostra. Nota-se, pelo anexo, que a etapa agrícola é responsável por ao menos $80 \%$ das emissões registradas na maioria das unidades produtoras. Tal constatação é relevante, uma vez que auxilia as usinas a direcionarem seus esforços na busca por melhores notas de eficiência energético-ambiental e receitas com a comercialização de CBIOs. 
Figura 3. Estatísticas descritivas da emissão de créditos de descarbonização.

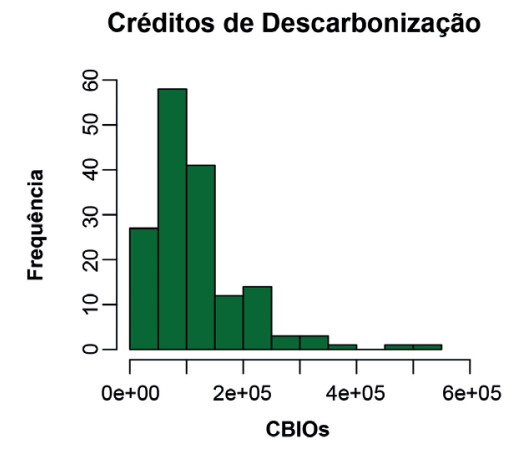

CBIOs por quantidade de cana

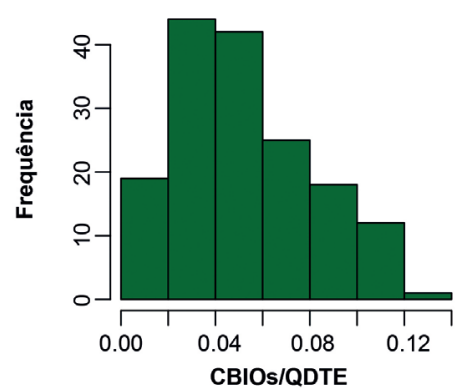

CBIOs por área total

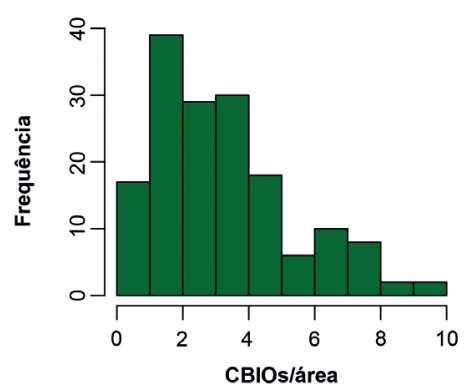

CBIOs por litros de etanol

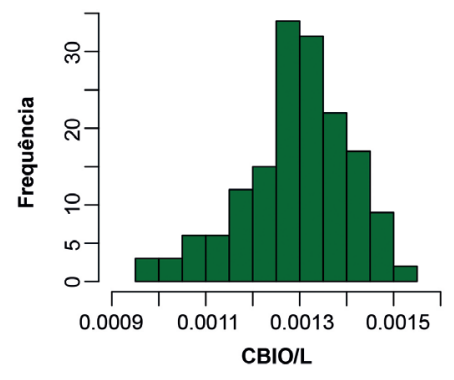

Fonte: Consulta Pública RenovaBio; dados da pesquisa (2019; 2020).

A Figura 4 mostra a posição das unidades produtoras com relação às medidas de intensidade de carbono na etapa agrícola e a área cultivada com cana-de-açúcar. O tamanho das bolas expressa o percentual de área de cana queimada para colheita em cada unidade produtiva. As 72 usinas mais intensivas em emissões na etapa agrícola, com valor da intensidade superior à média da amostra de $23 \mathrm{~g}$ CO2eq/MJ, ocupam 45\% da área total cultivada e têm a média de 45 mil hectares de área cultivada. Por outro lado, as 89 usinas com intensidade de emissões inferior à média da amostra ocupam 55\% das lavouras de cana e têm em média 34 mil hectares de área cultivada. Com base nesses dados, pode-se indicar a presença de deseconomias de escala em intensidade de emissões na etapa agrícola, uma vez que as unidades com maior área cultivada emitem GEEs de forma mais intensiva.

Conforme descrito na introdução deste estudo, optou-se por classificar as usinas em clusters e analisar de modo agregado aquelas que possuem características semelhantes. Para isso foram criados quatro clusters (1, 2, 3 e 4), que agruparam, respectivamente, 65, 67, 6 e 23 unidades. A Tabela 1 mostra os valores médios de cada cluster, com base em variáveis relacionadas à produção de etanol e emissão de CBIOs. Depreende-se da Tabela 1 que os clusters 3 e 4 abrangem as unidades de maior escala produtiva. 
Figura 4. Dispersão das unidades da amostra - Intensidade de carbono x área total.

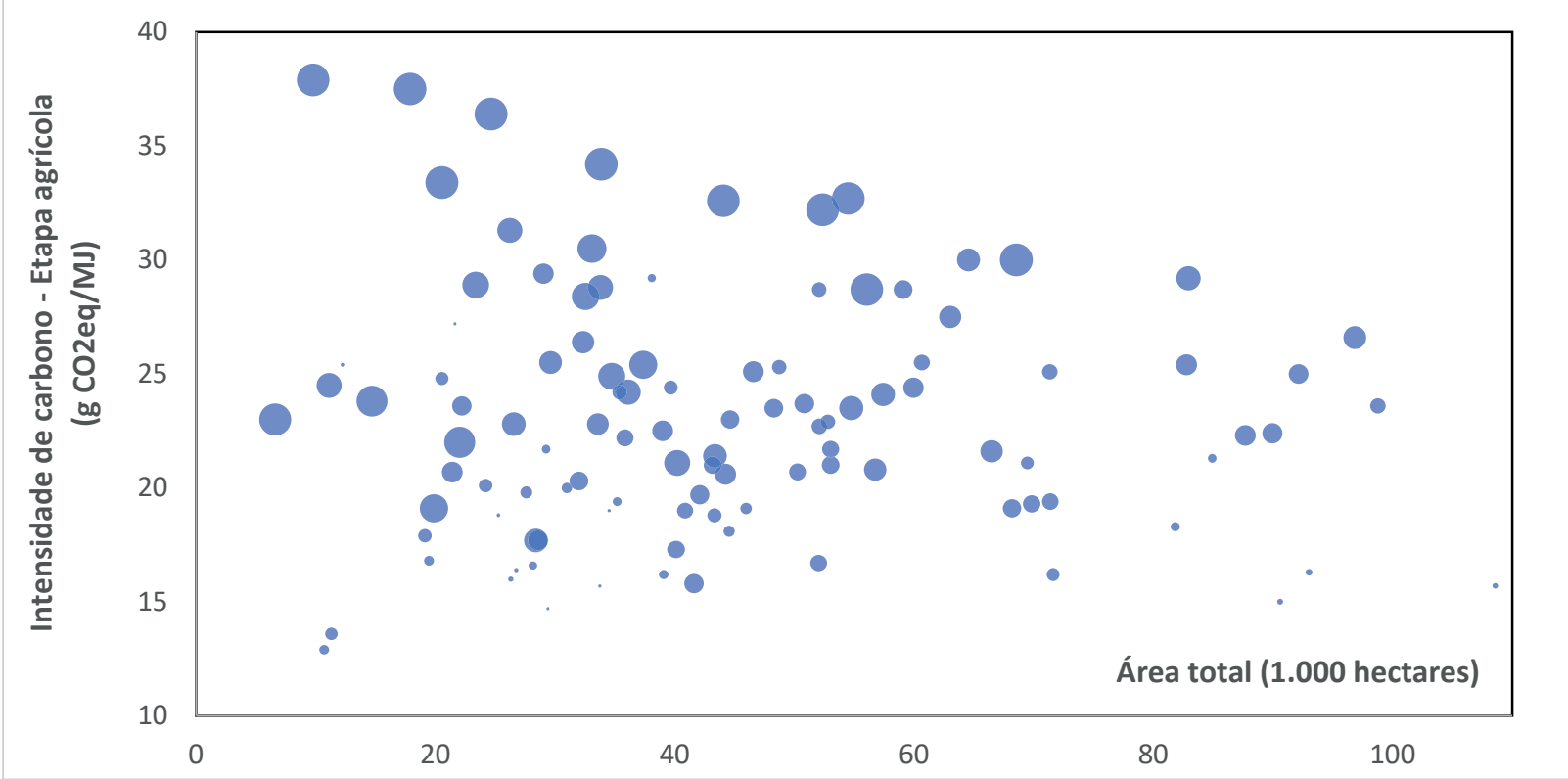

Fonte: Consulta Pública RenovaBio; dados da pesquisa $(2019 ; 2020)$.

Tabela 1. Valores médios dos clusters obtidos por $K$-means.

\begin{tabular}{|ccccc|}
\hline Cluster & $\begin{array}{c}\text { Área total } \\
\text { (ha) }\end{array}$ & $\begin{array}{c}\text { Cana-de-açúcar } \\
\text { processada } \\
(\mathbf{t})\end{array}$ & $\begin{array}{c}\text { Etanol produzido } \\
\text { (L) }\end{array}$ & CBIOs \\
\hline $1(n=65)$ & 34.895 & 1.934 .825 & 39.545 .742 & 51.080 \\
\hline $2(n=67)$ & 46.884 & 2.362 .284 & 90.441 .138 & 117.198 \\
\hline $3(n=06)$ & 75.558 & 4.203 .900 & 286.649 .336 & 380.712 \\
\hline $4(n=23)$ & 60.159 & 3.874 .260 & 171.962 .122 & 222.513 \\
\hline
\end{tabular}

Fonte: Consulta Pública RenovaBio; dados da pesquisa (2019; 2020).

A avaliação das emissões de CBIOs por área cultivada indica que as usinas do cluster 1 são mais eficientes, do ponto de vista ambiental, com a média de 1 CBIO obtido a cada 1,46 ha de cana cultivado. Em comparação, as unidades do cluster 3 obtiveram o pior desempenho e "produziram" 1 CBIO para cada 5,03 ha cultivados, em média. Com relação à emissão de CBIOs por litro de etanol hidratado produzido nas usinas, constatou-se que, em todos os clusters, foi necessário produzir aproximadamente $8 \mathrm{~L}$ de etanol hidratado para cada CBIO.

Já a análise da emissão de créditos de descarbonização por quantidade de cana processada indica que o cluster 3 foi o mais eficiente, obtendo em média $1 \mathrm{CBIO}$ a cada $11 \mathrm{t}$ de cana. $\mathrm{O}$ resultado da emissão por tonelada de cana processada é especialmente relevante para os produtores de cana, que podem utilizar esses valores para negociar novos modelos de remuneração. Em geral, usinas localizadas em regiões de cultivo com características de solo e clima semelhantes registraram resultados ambientais semelhantes. Do mesmo modo, usinas pertencentes a um grupo econômico tiveram resultados próximos. 
Para estimar as receitas obtidas com a comercialização de CBIOs foram traçados três cenários de preços da tonelada de carbono equivalente ( $\mathrm{C} \mathrm{CO}^{2}$ eq.): otimista, neutro e pessimista. O cenário otimista (US\$ 25/t CO² eq.), de maior preço, adota como referência o valor nominal médio da tonelada de carbono comercializada na União Europeia em 2019, no mercado estabelecido pelo programa EU Emissions Trading System (EU ETS). O cenário neutro (US\$ 11/t CO2 eq.) está baseado no valor nominal médio da tonelada de carbono comercializada em 2019 no mercado de carbono do programa piloto que envolve agentes da cidade de Pequim: The Beijing pilot ETS. Já no cenário pessimista (US\$ 6/t CO $\mathrm{CO}^{2}$ eq.), o preço da tonelada é equivalente ao valor nominal em dólares da taxa de carbono cobrada em 2019 sobre combustíveis líquidos, institucionalizada pelo governo argentino. A Tabela 2 apresenta os valores médios da receita obtida nos diferentes cenários.

Tabela 2. Valores nominais médios da receita obtida com créditos de descarbonização (CBIOs) - US\$ correntes de 2019.

\begin{tabular}{|c|c|c|c|}
\hline Cluster & $\begin{array}{c}\text { EU ETS - } \\
\text { US\$ } 25 / \text { t CO } \text { CO }^{2} \text {. }\end{array}$ & $\begin{array}{l}\text { Beijing Pilot ETS - } \\
\text { US\$ 11/t CO }{ }^{2} \mathrm{eq} \text {. }\end{array}$ & $\begin{array}{l}\text { Argentina Tax - } \\
\text { US\$ } 6 / \mathrm{CO}^{2} \mathrm{eq}\end{array}$ \\
\hline 1 & 1.276 .996 & 561.878 & 306.479 \\
\hline 2 & 2.929 .954 & 1.289 .180 & 703.189 \\
\hline 3 & 9.517 .805 & 4.187 .834 & 2.284 .273 \\
\hline 4 & 5.562 .832 & 2.447 .646 & 1.335 .080 \\
\hline
\end{tabular}

Fonte: Consulta Pública RenovaBio; dados da pesquisa (2019; 2020).

Pode-se, de modo exploratório, avaliar o acréscimo no preço do etanol causado pelo repasse dos custos resultantes da compra dos CBIOs pelas empresas distribuidoras de combustíveis. No cenário otimista, por exemplo, o litro de etanol sofrerá acréscimo de US\$ 0,03 centavos, caso as empresas distribuidoras de combustíveis repassem integralmente o custo dos CBIOs aos varejistas de combustíveis. Esse valor corresponde a $\mathrm{R} \$ 0,15$ centavos, com a taxa de câmbio PTAX vigente no momento da redação deste artigo, e equivale a aproximadamente $7 \%$ do preço do etanol hidratado combustível no estado de São Paulo, divulgado em Cepea/Esalq no mesmo período. No cenário pessimista, o custo do CBIO por litro de etanol foi de US\$ 0,007 centavos.

\section{Conclusão}

RenovaBio é uma política pública que incentiva ganhos de sustentabilidade nas atividades de transporte e a substituição da importação de combustíveis fósseis por biocombustíveis. $\mathrm{O}$ principal mecanismo indutor dessas mudanças é a formação de um mercado nacional de créditos de descarbonização, estruturado a partir de um esquema do tipo captura e negociação (cap and trade), que atribui receita extra às usinas ofertantes de créditos de descarbonização (CBIOs). Do lado da demanda de CBIOs, a RenovaBio institui metas anuais de descarbonização às empresas distribuidoras de combustíveis e estipula as punições cabíveis ao descumprimento das metas individuais.

No presente estudo foi possível constatar que o total de créditos de descarbonização obtido pelas usinas é diretamente influenciado pelo volume de produção de biocombustíveis. Embora um 
incentivo à sustentabilidade da produção, a nota de eficiência energético-ambiental tem impacto reduzido no volume de CBIOs emitido pelas usinas. Os resultados obtidos no artigo apontam que a etapa agrícola de produção deve ser priorizada na busca por melhores notas de eficiência energético-ambiental. A receita adicional das usinas que comercializarem CBIOs poderá elevar os preços dos biocombustíveis pagos pelo consumidor final, e assim diminuir a competitividade em face dos combustíveis fósseis. Pesquisas futuras poderão avaliar a potencial perda de mercado dos biocombustíveis em modelos de equilíbrio geral desse mercado, assim como questões relacionadas aos impactos distributivos dos CBIOs.

\section{Referências}

ASSOCIAÇÃO BRASILEIRA DAS ENTIDADES DOS MERCADOS FINANCEIRO E DE CAPITAIS - ANBIMA. Guia de Operacionalização do CBIO: crédito de descarbonização por biocombustíveis. São Paulo, 2019.

BRASIL. Contribuição Pretendida e Nacionalmente Determinada (iNDC) para Consecução do Objetivo da Convenção-Quadro das Nações Unidas sobre Mudança do Clima. Brasília, DF, 2016a. Disponível em: http://www.itamaraty.gov.br/ images/ed_desenvsust/BRASIL-iNDC-portugues.pdf. Acesso em: 5 dez. 2019.

BRASIL. Lei n. ${ }^{\circ}$ 13.576/2017, de 26 de dezembro de 2017. Dispõe sobre a Política Nacional de Biocombustíveis (RenovaBio) e dá outras providências. Brasília, DF, 2017a.

BRASIL.MinistériodeMinaseEnergia.NotaexplicativasobreapropostadecriaçãodaPolítica Nacionalde Biocombustíveis. Brasília,DF, 2017b. Disponívelem:http:/antigo.mme.gov.br/documents/36224/460049/ RenovaBio+-+Nota+Explicativa.pdf/08c6adbe-afea-5456-514e-e2bc9b6a30d0?version=1.0\#: :text=Privilegiar $\% 20 \mathrm{e} \% 20$ incentivar $\% 20$ solu $\% \mathrm{C} 3 \% \mathrm{~A} 7 \% \mathrm{C} 3 \% \mathrm{~B} 5 \mathrm{es} \% 20$ que, brasileira $\% 2 \mathrm{C} \% 20$ no $\% 20$ menor $\% 2$ 0prazo\%20poss\%C3\%ADvel. Acesso em: 10 dez. 2019.

BRASIL. Ministério do Meio Ambiente. Estratégia nacional de implementação da NDC do Brasil. Brasília, DF, 2016b. Disponível em: https://antigo.mma.gov.br/images/arquivo/80051/NDC/documento_base_ndc_2_2017.pdf. Acesso em: $10 \mathrm{dez} .2019$.

DA COSTA SILVA, R. W.; DE PAULA, B. L. Causa do aquecimento global: antropogênica versus natural. Terræ Didatica, v. 5, n. 1, p. 42-49, 2009.

FARINA, E. et al. Cenários de desafios no setor sucroenergético. AgroANALYSIS, v. 38, n. 5, p. 30-36, 2019.

INTERGOVERNMENTAL PAINEL ON CLIMATE CHANGE - IPCC. Climate change and land: an IPCC special report on climate change, desertification, land degradation, sustainable land management, food security, and greenhouse gas fluxes in terrestrial ecosystems. Genebra, 2019.

JARDIM, A. RenovaBio: revolução econômica e socioambiental. AgroANALYSIS, v. 37, n. 12, p. 48, 2018.

LEITE, J. C. Do mistério das eras do gelo às mudanças climáticas abruptas. Scientiae Studia, v. 13, n. 4, p. 811-839, 2015.

MARCOVITCH, J.; MACHADO FILHO, C. A. P.; GLERIANI, T. C. (Org.). A governança ambiental e seus compromissos. São Paulo: FEA/USP, 2019. Disponível em: https://www.usp.br/mudarfuturo/cms. Acesso em: 10 jun. 2019. 
MATSUURA, M. I. S. F. et al. Nota técnica - RenovaCalcMD: método e ferramenta para a contabilidade da intensidade de carbono de biocombustíveis no Programa RenovaBio. Rio de Janeiro: ANP, 2018. Disponível em: http://www.anp.gov.br/images/Consultas_publicas/2018/n10/CP10-2018_Nota-TecnicaRenova-Calc.pdf. Acesso em: 10 abr. 2019.

MOLION, L. C. B. Aquecimento global: uma visão crítica. Revista Brasileira de Climatologia, v. 3, p. 7-24, ago. 2008.

NASTARI, P. Renovabio: integrar as Políticas Agroindustrial e Energética. AgroANALYSIS, v. 38, n. 5, p. 19, 2019.

ORGANIZAÇÃO DAS NAÇÕES UNIDAS - ONU. Convenção-Quadro das Nações Unidas para mudanças climáticas: Acordo de Paris 2015. New York, 2015. Disponível em: https://brasil.un.org/sites/ default/files/2020-08/Acordo-de-Paris.pdf Acesso em: 10 jun. 2019.

PEREIRA, G.; ROITMAN, T.; GRASSI, C. O planeta, o Brasil e o RenovaBio. São Paulo: FGV, 2018. p. 19-23. (Boletim de Conjuntura, n. 8).

RAMSTEIN, C. et al. State and trends of carbon pricing 2019. New York: The World Bank, 2019.

RATHMANN, R. et al. Trajetórias de mitigação e instrumentos de políticas públicas para alcance das metas brasileiras no acordo de Paris. Brasília, DF, MCTIC, 2017.

REI, F. C. F.; GONÇALVES, A. F.; SOUZA, L. P. Acordo de Paris: reflexões e desafios para o regime internacional de mudanças climáticas. Veredas do Direito, v. 14, n. 29, p. 81-99, maio/ago. 2017.

SCACHETT, M. T. et al. A Renovacalc aplicada ao biocombustível etanol de cana-de-açúcar. In: CONGRESSO BRASILEIRO SOBRE GESTÃO DO CICLO DE VIDA, 6., 2018, Brasília, DF. Anais... Brasília, DF: Ibict, 2018a. p. 150-154.

SCACHETT, M. T. et al. RenovaCalc: a calculadora do programa RenovaBio. In: CONGRESSO BRASILEIRO SOBRE GESTÃO DO CICLO DE VIDA, 6., 2018, Brasília, DF. Anais... Brasília, DF: Ibict, 2018b. p. 150-154.

VITAL, M. H. F. Aquecimento global: acordos internacionais, emissões de CO2 e o surgimento dos mercados de carbono no mundo. BNDES Setorial, v. 24, n. 48, p. 167-244, set. 2018. 


\section{Anexo}

Anexo 1 - Intensidade de carbono por etapa da produção de etanol hidratado

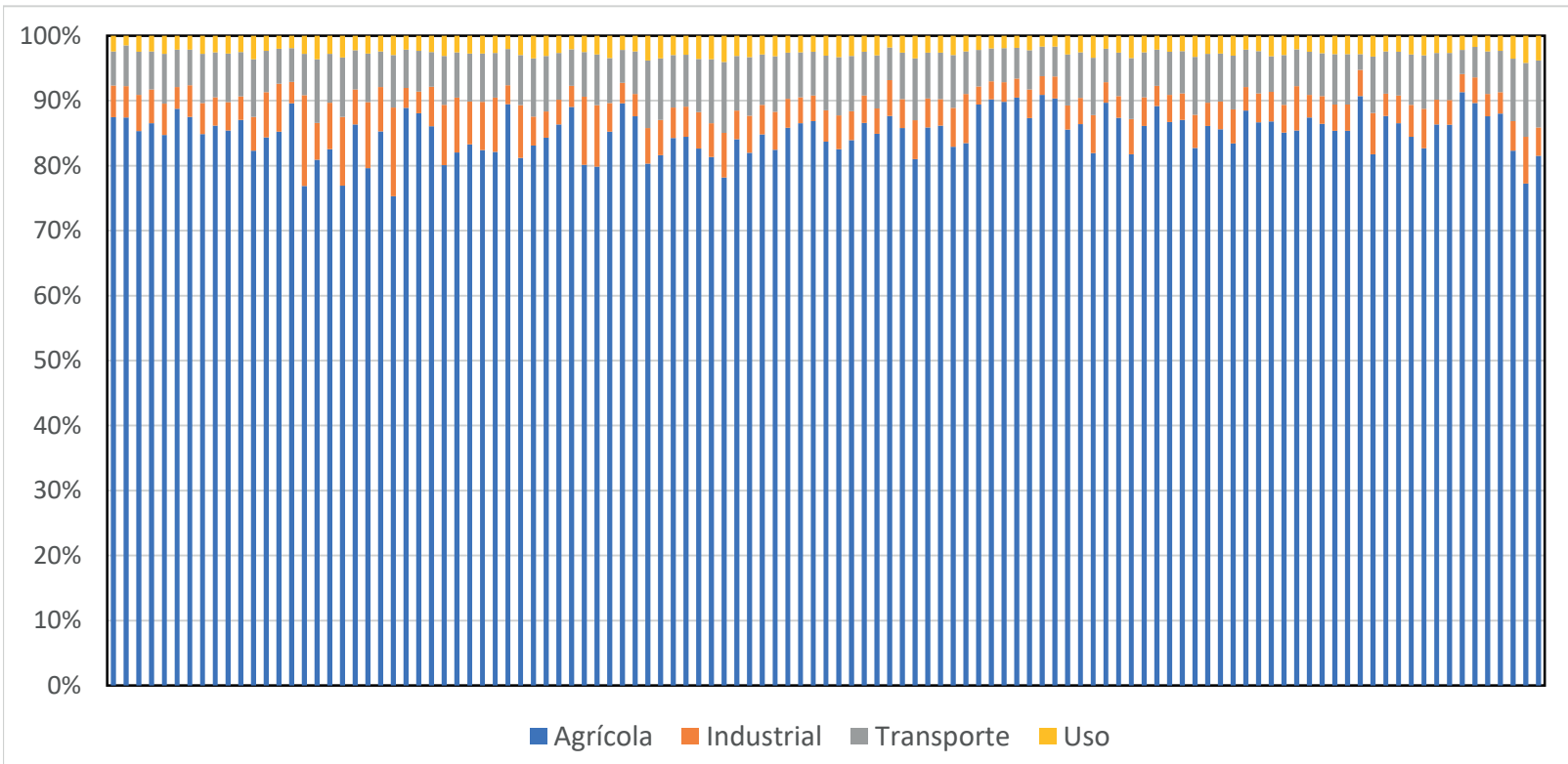

Fontes: Consulta Pública RenovaBio, dados da pesquisa $(2019 ; 2020)$. 
